\title{
El efecto de la experiencia democrática en la estructura de la legitimidad en América Latina y el Caribe
}

\author{
Luciana Fernandes Veiga \\ Ednaldo Ribeiro \\ María Alejandra Nicolás \\ Rachel Callai Bragatto
}

\section{Introducción}

Este artículo se enfoca en la estructura de la legitimidad de la democracia en Latinoamérica y el Caribe analizando en qué medida la experiencia democrática, tanto de los ciudadanos cómo de los países, influye en la evaluación del régimen como un valor (dimensiones más difusas) y como un sistema práctico (dimensiones más específicas). Específicamente, este artículo evalúa la forma en que la edad de los ciudadanos y los años de experiencia democrática de cada país influyen en las disposiciones individuales en relación a la democracia en términos de apoyos difusos y específicos.

La gran mayoría de los países latinoamericanos y caribeños formaron parte de diversos procesos de democratización en los últimos veinte años. En este contexto histórico, la literatura académica se ha enfocado en evaluar el carácter multidimensional del apoyo a la democracia. Sin embargo, en cuanto más se avanza en la investigación, más se constata la paradoja entre un alto apoyo a la democracia como un ideal y una evaluación negativa en cuanto a su desempeño. ¿Qué dimensiones están presentes en la fuente de legitimidad en sus aspectos más difusos (sistema de valor) y específicos (sistema práctico)? ¿De qué manera la experiencia con otros regímenes no democráticos puede influir en las diferentes dimensiones de la legitimidad de la democracia?

El apoyo a la democracia posee un carácter multidimensional, que no puede ser medido por una simple pregunta de cuestionario. Por ese motivo resulta necesario descomponer el rompecabezas que conforma su estructura y legitimidad. Esta estructura de la legitimidad está compuesta por las siguientes dimensiones, de la más difusa a la más específica: comunidad política, principios del régimen, instituciones políticas, desempeño del régimen, apoyo a las autoridades y actores políticos y, por último, gobierno local. Llamamos fuentes de legitimidad a aspectos que fundamentan el apoyo a cada una de las dimensiones de la legitimidad. De acuerdo con la literatura (Booth y Seligson, 2009), estas pueden ser: a) aspectos individuales sociodemográficos; b) aspectos individuales relacionados a valores y actitudes; c) aspectos estructurales relacionados a las características socioeconómicas y políticas de cada país. 
El primer conjunto de hipótesis analiza las dimensiones difusas de la legitimidad. La expectativa es que el apoyo difuso a la democracia será mayor entre aquellos que convivieron con regímenes autoritarios u oligárquicos. Tal experiencia haría posible el recuerdo del pasado represivo al contrastar el régimen democrático y no democrático (Morlino, 2007). Es decir, en lo que se refiere a la edad de los ciudadanos, si estos poseen una edad más avanzada y, por lo tanto, habrían vivido bajo gobiernos autoritarios, la adhesión a la democracia sería mayor. $Y$ aquellos más jóvenes, que no han tenido experiencias no democráticas, tendrían menos criterio de comparación y tomarían el sistema democrático casi como "natural". Siguiendo la misma lógica, en relación con la experiencia democrática de los países, aquellos ciudadanos de países con más años de experiencia con regímenes no democráticos u oligárquicos tendrían una mayor adhesión a la democracia en términos de apoyo difuso.

El segundo conjunto de hipótesis evalúa las dimensiones más específicas de la democracia. En dicho análisis, partimos del principio que en los países con mayor experiencia democrática, sus instituciones están más institucionalizadas y los ciudadanos más habituados con el ritmo y el accionar de la democracia. Lo anterior permitiría a los ciudadanos entender el complejo funcionamiento basado en la primacía de la ley, la separación de los poderes y la obligación de los gobiernos de rendir cuentas (Moisés y Carneiro, 2010). Mientras tanto, en los países en que la experiencia democrática se puede caracterizar como reciente, las instituciones estarían en proceso de consolidación y los individuos menos acostumbrados con la práctica democrática. Por tanto la evaluación del desempeño de la democracia sería más negativa que en países con mayor experiencia democrática. De la misma forma, esta lógica se aplicaría a nivel individual, los ciudadanos con más edad estarían más habituados con la democracia por lo que su evaluación sería más positiva.

Utilizamos el banco de datos del Barómetro de las Américas 2010 del Proyecto de Opinión Pública de América Latina (Lapop) ${ }^{1}$. Dicho proyecto incluye un total de 36.000 entrevistas realizada en veinticuatro países latinoamericanos (en cada país se realizaron 1,500 entrevistas). En lo que se refiere a los aspectos políticos, los países comparten una historia democrática relativamente reciente, todavía frágil y discontinua, siendo que el apoyo a la democracia ha crecido en las últimas décadas.

Aplicamos un análisis factorial y un modelo multinivel de regresión multivariada. Para estudiar las estructuras de la legitimidad partimos de veinticinco variables. A partir de éstas fueron creados seis índices, cada uno correspondiendo a una dimensión de la estructura de la legitimidad, y siendo compuesto por entre dos y nueve variables. Las dimensiones de la estructura de la legitimidad corresponden a nuestras variables dependientes. En un segundo nivel, buscamos identificar las fuentes relacionadas con cada una de las dimensiones en foco, considerando variables independientes en el nivel micro-

\footnotetext{
${ }^{1}$ Le agradecemos al Latin American Public Opinion Poll (Lapop) y sus patrocinadores (la Agencia de los Estados Unidos para el Desarrollo Internacional, el Banco Interamericano de Desarrollo y la Universidad de Vanderbilt) por disponer los datos.
} 
individual y en el nivel macro-estructural. En este artículo evaluaremos variables tanto a nivel individual como variables sociodemográficas, como aspectos estructurales relacionados a las características socioeconómicas y políticas de los países, dado que nuestras hipótesis evalúan la edad de los individuos y la experiencia democrática de los países latinoamericanos. Ya que esta estrategia empírica supone la combinación de variables a nivel individual y a nivel de cada país, optamos por construir un modelo multinivel (o jerárquico) para estimar los efectos relevantes sobre cada una de las dimensiones de la legitimidad seleccionadas (Raudenbush y Bryk, 2002)2.

\section{La experiencia con regímenes no democráticos y la reconstrucción de la democracia en América Latina y el Caribe: contextualización histórica}

En América Latina y el Caribe se contabilizan alrededor de cincuenta regímenes militares durante el siglo XX (Smith, 2005). No obstante, entre tales regímenes, aquellos instaurados a partir de las décadas de 1960 y 1970 reflejaban características diferentes de aquellos que habían sido establecidos en la región hasta entonces. Los objetivos, en términos generales, no eran únicamente eliminar las "fuerzas subversivas", sino también proponer una agenda económica y social para los países. Esto fue particularmente evidente en algunos países del cono sur (Argentina, Brasil y Uruguay), donde los regímenes militares estrecharon fuertes lazos con tecnócratas económicos y podrían ser definidos como "regímenes de excepción que no buscan alterar la naturaleza capitalista-liberal del Estado" (Cheresky y Chonchol 1986, p. 15) ${ }^{3}$. Dichos regímenes contaban con una tendencia a la "destrucción del estado social", dada la transferencia de las tareas sociales del Estado en educación, asistencia social y salud a favor del sector privado. Igualmente, se sumó la vigilancia ideológica del comportamiento social, el uso de la violencia física y una reducción notable de los espacios de representación pública.

En referencia a la reconstrucción de la democracia a partir de la década de 1980, la región pasó por el desafío de reconstruir sus instituciones políticas paralelamente a los retos ya impuestos por la realidad económica y social de la época. Una de las visiones académicas que dominaron en el inicio de los años de 1990 (Mainwaring, 1990; Mainwaring y Shugart, 1993) sugería que el tipo de presidencialismo que estaba generalizándose en los países de América Latina podría tener consecuencias negativas para la estabilidad democrática. El argumento residía en las características institucionales del modelo presidencialista, particularmente por combinar un jefe del Ejecutivo con fuertes poderes de agenda, multipartidismo y representación proporcional. Sin embargo, en la práctica, esa combinación terminó por ser muy difundida en la región (Chasquetti, 2003). Según Anastasia, Melo y Santos (2004), al reflexionar sobre las causas de esa situación en América Latina, subrayan las posibles combinaciones entre condiciones e instituciones. Es decir, el desafío de la construcción institucional con la combinación de desigualdades

\footnotetext{
2 Los modelos fueron estimados a través del software HLM 6.8 .

3 Traducción de los autores.
} 
estructurales. Por este motivo, diversos países realizaron cambios en la ingeniería institucional, especialmente reformas en el sistema electoral.

Cabe subrayar que la transformación de regímenes autoritarios por otros con características democráticas implica reflexionar, por un lado, sobre los procesos de democratización y, por otro, sobre la calidad de la democracia en los países de América Latina y el Caribe. El proceso de democratización se refiere a la transformación de regímenes políticos de naturaleza autoritaria en otros con características democráticas (Moisés, 2008). En un análisis detallado sobre el tema, también está en juego la transición de una democracia limitada a una democracia en sentido pleno. Sobre este tema se teorizó bastante, sin embargo, fue O'Donnell (1991) con su análisis sobre los procesos de transición y consolidación de las democracias en América Latina quien suscitó la mayor polémica por su caracterización de "democracias delegativas" a diversos países de la región. Algunas democracias recientes como Argentina, Brasil, Perú, Ecuador y Bolivia, son democracias que cumplen con los criterios de Dahl (1989) para la definición de poliarquía. Sin embargo, presentan un conjunto de características que llevaron a O'Donnell a caracterizarlas como democracias delegativas, o sea, democracias no consolidadas o no institucionalizadas. Cabe destacar que en los países analizados por el autor estaba vigente la dimensión electoral de la "accountability vertical". Por medio de elecciones libres y regulares, los ciudadanos podrían ser capaces de castigar o premiar a los gobernantes votando a favor o en contra de ellos en la próxima elección. También podían organizarse para expresar libremente sus opiniones y demandas. No obstante, se percibía una debilidad en la "accountability horizontal", entendida como el conjunto de agencias estatales con autoridad legal para emprender acciones de control y sanciones legales a otros actores estatales.

Ahora bien, una paradoja en América Latina es el alto apoyo a la democracia y, al mismo tiempo, una baja satisfacción con el régimen, frecuentemente registrada en diversos estudios sobre cultura política. Como diversos autores señalan, la convivencia entre esas distintas lógicas de adhesión puede contribuir para operar procesos desestabilizadores, retrocesos y cierta erosión de apoyo al sistema, generando individuos cada vez más descreídos, es decir, con cierto cinismo político para utilizar el concepto desarrollado por Putnam (2000). En otras palabras, ocurre una creciente valorización de la democracia como un ideal y, por otro lado, una evaluación negativa de su desempeño (Moisés, 2005; Norris, 1999; Lagos, 2000; Gunther y Monteiro, 2003).

\section{Estructura y fuente de la legitimidad: revisión de la literatura}

La literatura recurre a dos principales tradiciones teóricas para abordar la relación entre las actitudes de los ciudadanos y la evaluación de la democracia. La primera es la cultura política, la cual los autores pioneros Almond y Verba (1989) la refieren como "orientaciones específicas - actitudes en relación al sistema político y sus varias partes y 
actitudes en relación al papel del individuo en el sistema" (Almond y Verba, 1989, p. 12) La segunda, la teoría institucionalista (Muller y Seligson, 1994) parte del principio que la democracia debe ser evaluada por medio del desempeño de los gobiernos, sus instituciones y la relación entre los diferentes poderes. El énfasis recae sobre las condiciones más estructurales en que se desarrolla el juego democrático, es decir, el diseño institucional de los sistemas, y también sobre requisitos mínimos como la existencia de elecciones abiertas y libres, la competencia entre los partidos políticos, la libertad de expresión y el acceso a medios de información no oficiales (permitiendo el control de los gobernantes).

En lugar de adoptar alguna de esas teorías, asumimos que la adhesión a la democracia no es únicamente marcada por los valores sustentados por los ciudadanos ni por la evaluación que hacen del desempeño del régimen. A pesar de que las teorías culturalista e institucionalista divergen, ambas visiones ofrecen el sustento teórico para perspectivas como las construidas por Booth y Seligson (2009), Dalton (2004), Klingemann (1999), Norris (1999) y otros, que buscan superar dicha dicotomía.

Para entender la naturaleza multidimensional del concepto de legitimidad y adhesión al sistema político resulta necesario revisar los conceptos de apoyo difuso y específico de Easton (1999), quien realizó un aporte teórico y metodológico considerable para entender la legitimidad política. El primer tipo de apoyo está ligado a sentimientos comunitarios de pertenencia y de lealtad, a través de los cuales los individuos se sienten vinculados al sistema. Este tipo de apoyo no involucra un cálculo racional, es independiente de las ventajas individuales que su vinculación traería a los miembros del sistema. El apoyo específico se relaciona con la satisfacción de los individuos al verificar que sus demandas fueron acatadas por las instancias o centros de poder del sistema. Las demandas de los individuos están sujetas al momento histórico y a la cultura. Cuando las demandas son desatendidas de forma regular y continua, el apoyo específico tiende a disminuir considerablemente. Easton subdividió el concepto de apoyo político - que él ya denominaba de legitimidad - en componentes generales, vinculados a valores básicos y en componentes más específicos, relacionados al desempeño de las instituciones (Seligson, Booth y Gómez, 2006).

Tal como Booth y Seligson (2009) apuntan, Norris (1999) y Dalton (1999, 2004) rescatan conceptualmente los tipos de apoyo político de Easton con el objetivo de profundizar el carácter multidimensional del concepto de apoyo al sistema político. Los autores parten de la distinción que Easton realiza entre el apoyo a la comunidad, al régimen y a las autoridades. Para Easton, el régimen constituye la estructura básica para gobernar el país, de esta forma, las personas no pueden aprobar algunos elementos y rechazar otros. Sin embargo, estudios recientes han presentado evidencia que los individuos son capaces de distinguir los diferentes niveles del régimen. Lo que implica que los ciudadanos

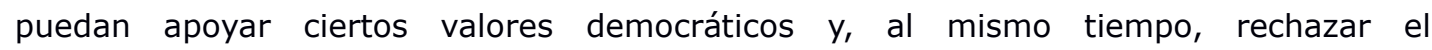
funcionamiento del parlamento $u$ otras instituciones del gobierno representativo.

\footnotetext{
4 Traducción de los autores.
} 
Booth y Seligson (2009) destacan que Norris (1999) propone cinco objetos de apoyo político, que a su vez definen diferentes niveles de apoyo: la comunidad política, los principios, el desempeño, las instituciones y los actores en el poder. Estos niveles pueden ser vistos desde un apoyo difuso, anclado en el apoyo al país, hasta un nivel más concreto, sustentado por el apoyo a líderes políticos. Para los dos autores, el punto fundamental a destacar es que el apoyo político debe ser entendido como un fenómeno multidimensional y complejo.

Da la misma forma, Booth y Seligson (2009) destacan que Klingemann (1999) a partir de un análisis factorial verificó la cohesión entre los componentes de las cinco dimensiones estructurales de legitimidad democrática propuestas por Norris, quien no llegó a analizarlas empíricamente. Considerando treinta y ocho países y utilizando datos del World Values Survey (1990), el autor encontró evidencia de la consistencia en tres de las dimensiones propuestas para la composición del régimen. El estudio de Klingemann fue realizado a partir de datos agregados, de esta forma no se puede afirmar que sea igualmente consistente con el nivel individual.

Posteriormente, Dalton (2004) centró su estudio en ocho naciones consideradas democracias avanzadas y utilizó datos del World Values Survey de 1995 a 1998 . Verificó cuatro de las cinco dimensiones de la estructura de la legitimidad, omitiendo el desempeño del régimen, y también transformó el apoyo a valores democráticos en apoyo a la democracia. A partir del análisis factorial varimax rotation concluyó que estas dimensiones son consistentes y están fuertemente correlacionadas en la estructura de la legitimidad democrática

Para la discusión de este tema, nos interesa explorar el debate acerca de la estructura y de las fuentes de la legitimidad. A partir de lo que Norris (1999) y Dalton (1999) ya habían presentado, Booth y Seligson (2009) apuntan seis dimensiones de la estructura de la legitimidad política, agregando el apoyo al gobierno local a las dimensiones originales. Los autores confirman el carácter multidimensional en la composición de la estructura de la legitimidad en el contexto latinoamericano, considerando una encuesta realizada en ocho países de la región en 2004. Para el presente estudio serán consideradas las seis dimensiones de la estructura de la legitimidad de Booth y Seligson (2009), siguiendo los estudios pioneros de Dalton (1999), Norris (1999) y Easton (1999).

Dejando ahora de lado el estudio de la estructura de la legitimidad y pensando en la fuente de ésta, se busca entender qué factores llevan a los ciudadanos a apoyar al régimen democrático. La discusión sobre la fuente de legitimidad está presente en las teorías más institucionalistas sobre el tema. Estas apuntan hacia tres fuentes principales de legitimidad: desempeño macro social del sistema político (como evaluación del gobierno); características de los ciudadanos (como aspectos socioeconómicos y demográficos); actitudes y experiencias de los ciudadanos en el nivel macro social (Booth y Seligson, 2009). En su discusión sobre las fuentes de legitimidad, Booth y Seligson (2009) contemplan factores contextuales, históricos, institucionales y de desempeño social en el nivel macro, así como características sociodemográficas de los ciudadanos en el nivel 
micro. En su estudio, pudieron medir el impacto de dichas fuentes en cada uno de los seis componentes de la estructura de la legitimidad. La lógica era que las fuentes de la legitimidad no impactaban de manera semejante en cada una de las dimensiones de la estructura de la legitimidad, y, en efecto su hipótesis fue confirmada: aspectos de la historia de la democracia impactan en el apoyo de la comunidad política y en los principios centrales del régimen. De igual forma, el desempeño del gobierno impacta en el apoyo a las instituciones democráticas y el crecimiento económico en el apoyo al desempeño del régimen.

En lo que se refiere a la pertinencia de adoptar la edad del ciudadano como variable explicativa, los autores propusieron dos hipótesis alternativas. La primera supone que en las democracias recientes, ciudadanos de mayor edad podrían mantenerse fiel al régimen no democrático en el cual vivieron. La segunda hipótesis supone que los ciudadanos de mayor edad deberían retener mejor el recuerdo de la represión del régimen dictatorial y evaluar el sistema democrático de manera más positiva que los jóvenes que no vivieron durante los años de la represión. Morlino también señala la asociación entre el apoyo difuso a la democracia y la experiencia con regímenes autoritarios u oligárquicos, una vez que tal experiencia posibilitaría el recuerdo del pasado represivo al contrastar un régimen democrático y uno no democrático (Morlino, 2007). Es decir, en lo que se refiere a la edad de los ciudadanos, si el individuo ha experimentado un gobierno autoritario (los individuos de edad más avanzada), su adhesión a la democracia sería mayor. En tanto que aquellos que vivieron solamente en regímenes democráticos (los más jóvenes) no tendrían criterios de comparación y tomarían el sistema democrático casi que como "natural".

(...) in new democracies, older citizens might retain allegiance to a prior nondemocratic regime. Or, in contrast, they might well have memories of prior dictatorial repression and therefore evaluate democratic systems more positively than the young who lack such experiences (Booth y Seligson, 2009, p. 114).

\section{Dimensiones de la legitimidad en América Latina y el Caribe y experiencia democrática: metodología}

Es necesario recordar que las seis dimensiones mencionadas anteriormente fueron propuestas a partir de los desarrollos teóricos de Easton (1999) y analizadas empíricamente en algunos casos latinoamericanos. En el caso de América Latina, el trabajo de Seligson, Booth y Gómez (2006) y de Booth y Seligson (2009) producen resultados interesantes usando, en el primer caso, datos de Costa Rica y, en el segundo, datos de ocho países de la región. Ribeiro (2008), con algunas adaptaciones, replica el modelo de análisis de esos trabajos para el escenario brasileño y obtiene resultados semejantes, mostrando que tal estructura parece ser consistente inclusive en contextos sociales y políticos distintos. En este artículo, buscamos investigar sobre esa multidimensionalidad para el contexto de América Latina contribuyendo a esa área de estudio. 
Primeramente, analizamos su pertinencia en América Latina y el Caribe. Para esto, utilizamos un análisis factorial, específicamente, un conjunto de métodos multivariados para reducir la dimensionalidad de un amplio conjunto de datos a un grupo menor de factores latentes (Hair, Anderson y Tatham, 1987). En nuestro caso específico, esa metodología permitirá verificar en qué medida las respuestas proporcionadas por los entrevistados a las diferentes preguntas se agrupan de forma congruente con las dimensiones teóricamente propuestas para dividir la legitimidad.

Como es posible verificar abajo (Tabla 1), el porcentaje de variación explicada por los seis factores es de $61.97 \%$, lo que es bastante robusto tratándose de un conjunto tan variado de cuestiones. Este resultado indica que parte considerable de la variación de las respuestas puede ser captada con esa reducción a apenas seis factores latentes ${ }^{5}$.

En relación con la distribución de las variables entre los factores, podemos observar una notable consistencia entre los datos empíricos y el modelo teórico propuesto. Las dos variables seleccionadas para componer la dimensión comunidad, ambas relacionadas al orgullo de la nacionalidad, obtuvieron en el factor cuatro cargas (factor loadings) elevadas (arriba de siete). Las variables relacionadas a la aprobación de la participación en manifestaciones, organizaciones y grupos a través del trabajo en campañas partidistas, seleccionadas para presentar la dimensión de los principios, reportaron cargas factoriales aún mayores en el factor dos. Las variables ligadas a la evaluación de las instituciones, a pesar de que componen un grupo considerablemente mayor y diverso, también revelaron consistencia robusta (de 0.64 a 0.78 ). Los factores cinco y seis confirman la hipótesis de Booth y Seligson (2009) respecto de la distinción entre la evaluación del gobierno local y esferas más amplias, dado que la evaluación de la situación económica nacional se distingue claramente de la evaluación de los servicios municipales. Además de estar en factores distintos, dichas evaluaciones presentan signos diferentes indicando criterio inverso de respuestas. El factor referente a la dimensión local es complementado por el nivel de confianza en el gobierno local, que de forma muy consistente no cargó en la dimensión general de las instituciones discutida anteriormente. En el factor tres podemos observar la reunión de un conjunto de variables que seleccionamos para componer la dimensión de la evaluación del desempeño de líderes o actores políticos en el poder. Todas las cuestiones que generaron esas variables interrogaban a los entrevistados sobre la actuación del gobierno actual o directamente sobre el desempeño del presidente y de los diputados. Como era de esperar, todas las variables, con excepción de la última (relativa a los diputados), cargaron consistentemente en el mismo factor. La variable sobre el desempeño de los diputados no carga en ninguno de los factores, lo que indica significativa independencia en relación a todas las dimensiones consideradas. En razón de esto, no fue incluida en el análisis que presentamos posteriormente.

\footnotetext{
${ }^{5}$ Las respuestas ausentes ("no sabe" y "no respondió") fueron excluidas en el momento de la preparación de los datos, por medio de procedimientos de recodificación. De esta forma, no entraron en los análisis.
} 
En resumen, dado el análisis anterior, consideramos la estructura de la dimensión de la legitimidad compuesta por seis ejes en el contexto de los países incluidos en este artículo.

Tabla 1

Dimensiones de la legitimidad en América Latina y Caribe

\begin{tabular}{|c|c|c|c|c|c|c|}
\hline \multicolumn{7}{|c|}{ Componente } \\
\hline & 1 & 2 & 3 & 4 & 5 & 6 \\
\hline Orgullo de la nacionalidad & 0,186 & 0,194 & 0,148 & 0,795 & 0,017 & 0,182 \\
\hline $\begin{array}{l}\text { Orgullo de la nacionalidad al oír el } \\
\text { himno }\end{array}$ & 0,122 & 0,018 & 0,097 & 0,794 & 0,059 & 0,096 \\
\hline $\begin{array}{l}\text { Aprobación de la participación - } \\
\text { manifestaciones }\end{array}$ & 0,076 & 0,827 & 0,008 & 0,025 & 0,006 & 0,034 \\
\hline $\begin{array}{l}\text { Aprobación de la participación - } \\
\text { organizaciones grupos }\end{array}$ & 0,062 & 0,852 & 0,028 & 0,149 & $-0,007$ & 0,23 \\
\hline $\begin{array}{l}\text { Aprobación de la participación - } \\
\text { campañas para partidos }\end{array}$ & 0,209 & 0,795 & 0,12 & 0,129 & 0,011 & 0,343 \\
\hline Evaluación de los tribunales de justicia & 0,645 & 0,043 & 0,326 & 0,014 & 0,105 & 0,079 \\
\hline Respeto por las instituciones políticas & 0,653 & 0,16 & 0,347 & 0,257 & 0,139 & 0,231 \\
\hline Orgullo del sistema político & 0,749 & 0,113 & 0,493 & 0,226 & 0,227 & 0,098 \\
\hline Preferencia por la democracia & 0,727 & 0,16 & 0,454 & 0,256 & 0,185 & 0,18 \\
\hline Confianza en la justicia & 0,788 & 0,079 & 0,46 & 0,095 & 0,123 & 0,23 \\
\hline Confianza en la Justicia Electoral & 0,724 & 0,151 & 0,459 & 0,097 & 0,124 & 0,087 \\
\hline Confianza en el Congreso & 0,752 & 0,087 & 0,507 & 0,086 & 0,138 & 0,156 \\
\hline Confianza en los partidos políticos & 0,671 & 0,074 & 0,451 & 0,002 & 0,081 & 0,123 \\
\hline Confianza en el Supremo Tribunal & 0,758 & 0,152 & 0,539 & 0,115 & 0,127 & 0,078 \\
\hline $\begin{array}{l}\text { Evaluación de la situación económica } \\
\text { nacional }\end{array}$ & 0,226 & $-0,026$ & 0,311 & 0,004 & 0,794 & 0,278 \\
\hline $\begin{array}{l}\text { Evaluación de la situación económica } \\
\text { nacional en comparación con el pasado }\end{array}$ & 0,178 & 0,057 & 0,312 & 0,079 & 0,808 & 0,103 \\
\hline Evaluación de los servicios municipales & 0,173 & 0 & 0,203 & 0,092 & 0,245 & 0,802 \\
\hline Confianza en el gobierno municipal & 0,54 & 0,097 & 0,413 & 0,137 & 0,015 & 0,63 \\
\hline $\begin{array}{l}\text { Evaluación del desempeño del gobierno } \\
\text { actual en el combate a la pobreza }\end{array}$ & 0,454 & 0,057 & 0,845 & 0,112 & 0,293 & 0,211 \\
\hline $\begin{array}{l}\text { Evaluación del desempeño del gobierno } \\
\text { actual en la defensa de los principios } \\
\text { del régimen }\end{array}$ & 0,545 & 0,121 & 0,847 & 0,127 & 0,246 & 0,123 \\
\hline $\begin{array}{l}\text { Evaluación del desempeño del gobierno } \\
\text { actual en el combate a la corrupción }\end{array}$ & 0,507 & 0,02 & 0,842 & 0,072 & 0,196 & 0,321 \\
\hline $\begin{array}{l}\text { Evaluación del desempeño del gobierno } \\
\text { actual en la seguridad pública }\end{array}$ & 0,531 & 0,058 & 0,84 & 0,126 & 0,184 & 0,065 \\
\hline $\begin{array}{l}\text { Evaluación del desempeño del gobierno } \\
\text { actual en la economía }\end{array}$ & 0,516 & 0,074 & 0,839 & 0,106 & 0,344 & 0,089 \\
\hline $\begin{array}{l}\text { Evaluación del desempeño del } \\
\text { presidente }\end{array}$ & 0,308 & 0,015 & 0,653 & 0,135 & 0,49 & 0,123 \\
\hline $\begin{array}{l}\text { Evaluación del desempeño de los } \\
\text { diputados }\end{array}$ & 0,412 & 0,019 & 0,495 & 0,035 & 0,379 & 0,177 \\
\hline
\end{tabular}

Fuente: Elaboración propia sobre la base de datos de Lapop, 2010.

Notas: Extracción por Análisis de Componente Principal y Rotación Oblimin1 con Normalización de Kaiser. 
EL EFECTO DE LA EXPERIENCIA DEMOCRÁTICA EN LA ESTRUCTURA DE LA LEGITIMIDAD EN AMÉRICA LATINA Y EL CARIBE

A partir de esos resultados, presentamos a continuación la composición de los índices que proponemos para presentar cada una de esas seis dimensiones, siguiendo un ordenamiento que va desde las difusas a las más específicas:

Comunidad política - La dimensión más difusa entre las seis se refiere al apoyo que los ciudadanos emiten a la comunidad política o al sentimiento de pertenencia a ella. Según Booth y Seligson (2009), la presencia de este apoyo implica en el reconocimiento de que existe una comunidad nacional que comparte intereses y preocupaciones. El índice fue compuesto por las variables "orgullo de la nacionalidad" y "orgullo de la nacionalidad al oír el himno", cuyos valores fueron recodificados en un índice que va de cero a diez. Sin embargo, como el factor no presenta distribución normal, ya que la mayoría presenta mucho orgullo - $90 \%$ tiene orgullo - y $10 \%$ no tiene orgullo, la solución fue convertir para el nivel dicotómico (bajo-medio $=0$ y alto $=1$ ) para que esta variable pudiera ser usada como dependiente en los modelos multiniveles logísticos.

Principios del régimen - Consiste en el agrupamiento de tres variables sobre la aceptación de diferentes formas de participación (manifestaciones, organizaciones, grupos, campañas para partidos). El resultado fue un índice que va de cero a veintisiete con distribución aproximadamente normal (asimetría de -0.53).

Instituciones políticas - El apoyo a las instituciones políticas es una de las formas más importantes de legitimidad. Fueron agrupadas variables sobre apoyo y confianza en las instituciones (instituciones políticas en general, sistema político, tribunal de justicia y supremo tribunal). El índice es bastante amplio: de 0 a 64 .

Desempeño del régimen - Buscamos medir la evaluación de la situación de la economía nacional más la evaluación retrospectiva de la situación económica. Todos los gobiernos buscan promover crecimiento económico, estabilidad de los precios y creación de empleos. A pesar de que los ciudadanos puedan tener alguna dificultad de acompañar punto por punto toda esta información, pueden llegar a tener una evaluación general de la economía al comparar su nivel actual con el nivel pasado y de esa forma construyen la evaluación del gobierno. El índice va de cero a seis y la distribución es normal.

Apoyo a las autoridades y actores políticos - Esta dimensión se relaciona con el desempeño del ejecutivo nacional al momento de realizarse la encuesta en 2010. Formada por cuestiones sobre la actuación del gobierno nacional en el combate a la pobreza y corrupción, así como en la seguridad pública, economía y defensa de los principios del régimen, además de su desempeño de manera general. La amplitud es de cero a treinta y cuatro y su distribución también es aproximadamente normal. 
Gobierno local - El apoyo al gobierno local fue agregado al conjunto por Booth y Seligson (2009) que apuntan que el poder municipal en América Latina, a diferencia de lo que ocurre en Estados Unidos, es responsable de muchos servicios públicos básicos como saneamiento, pavimentación, iluminación pública y recolección de residuos. Aquí fueron agrupadas las dos variables (evaluación de los servicios municipales y confianza en el gobierno municipal) a nivel municipal. El índice tiene amplitud de cero a diez, con distribución aproximadamente normal.

La Tabla 2 sintetiza toda esta información para la región y en el apéndice metodológico al final del texto se presenta la información dividida por países. Podemos verificar que las dos dimensiones más abstractas son en las cuales se presentan mayores medias en relación a sus amplitudes, sobre todo, la dimensión de la comunidad política. Todas las demás se aproximan a la mediana, indicando un escenario positivo, a pesar de sensiblemente desigual en la comparación entre la adhesión difusa y específica.

Tabla 2

Estadísticas descriptivas de las dimensiones de la legitimidad

\begin{tabular}{|l|c|c|c|c|c|c|}
\hline & N & Mínimo & Máximo & Media & $\begin{array}{c}\text { Desviación } \\
\text { estándar }\end{array}$ & Asimetría \\
\hline Comunidad política dicotómica & 35586 & 0 & 1 & 0,89 & 0,31 & $-2,526$ \\
\hline Principios del régimen & 34405 & 0 & 27 & 18,75 & 6,684 & $-0,53$ \\
\hline Instituciones políticas & 30471 & 0 & 54 & 26,83 & 11,483 & $-0,096$ \\
\hline Desempeño & 35014 & 0 & 6 & 2,63 & 1,364 & 0,028 \\
\hline Líderes y actores políticos & 32052 & 0 & 34 & 16,22 & 8,078 & $-0,01$ \\
\hline Gobierno local & 33039 & 0 & 10 & 5 & 2,298 & $-0,157$ \\
\hline
\end{tabular}

Fuente: Elaboración propia sobre la base de datos de Lapop, 2010.

Pasamos a la identificación de las fuentes seleccionadas en cada una de las dimensiones, considerando variables dependientes en el nivel micro (individual) y en el nivel macro estructural. Lo que llamamos fuentes se refieren a aspectos que fundamentan el apoyo a cada una de las dimensiones de la legitimidad. Como vimos en la revisión de la literatura, en este artículo evaluaremos variables relativas a los aspectos individuales sociodemográficos y a los aspectos estructurales relacionados a las características socioeconómicas y políticas de los países.

Para agregar variables independientes macro y micro en un análisis de regresión, adoptaremos los modelos jerárquicos que, diferentemente de los modelos de regresión convencionales, permiten que datos generados en distintos niveles empíricos sean agregados en una única ecuación (Raudenbush y Bryk, 2002). Con esa metodología será posible evaluar si cada una de las dimensiones de la legitimidad seleccionadas posee una base efectivamente macro y micro o si apenas uno de esos niveles de condicionamientos actúa como condicionante. Una vez confirmada esa doble dimensión del fenómeno, ese procedimiento puede indicar que porcentaje de la variación en esas dimensiones se debe a cada una de las variables individuales y nacionales, bien como al conjunto integrado de todos los predictores. 
En el nivel micro, adoptaremos como variables explicativas la edad del entrevistado, así como el sexo y la escolaridad del mismo. Las dos últimas variables son variables de control. Las variables independientes del nivel macro utilizadas son el nivel de desarrollo económico y social, en base al Índice de Desarrollo Humano de las Naciones Unidas (IDH), que combina Producto Bruto Interno (PBI) per cápita, mortalidad infantil y metas de educación, y la fase de consolidación del régimen democrático, en base al índice de Freedom House. Ambas son variables de control. La variable explicativa macro/estructural central para nuestra discusión son los años de experiencia democrática de los países (ininterrumpida). Los años de democracia ininterrumpida se refieren al número de años que un país ha mantenido su sistema democrático (no oligárquica y no dictatorial) después de la "tercera ola" de democratización conceptualizada por Huntington (1994). La fuente proviene de la clasificación de Smith (2005).

En este artículo serán analizados veinticuatro países de América Latina y el Caribe (ver anexo, Tabla 1). Para cada país fueron realizadas 1500 entrevistas en 2010 por el Barómetro de las Américas (Lapop).

\section{Resultados y discusión}

Iniciamos analizando la dimensión de apoyo a la comunidad política, recordando que esa medida está codificada como dicotómica, lo que nos obliga a utilizar un modelo multinivel logístico para estimar sus predictores y verificar nuestras hipótesis de trabajo. Inicialmente construimos un modelo ANOVA para estimar cuanto de la variación en la probabilidad de apoyar la comunidad política se debe a los factores de nivel uno y dos. Ese modelo estimó la razón de probabilidad media de apoyo entre los países en 2.11 y la varianza entre los países en términos de las medias de las razones de probabilidades en 0.40. Con base en esta última información deberíamos calcular el coeficiente de correlación interclase (CCI) a partir de esa fórmula:

\section{Fórmula 1}

$$
\rho=\frac{\tau_{00}}{\tau_{00}+\sigma^{2}}
$$

Así obtenemos una medida de la proporción que se debe al nivel de los países. Sin embargo, ese cálculo se aplica únicamente a los modelos multiniveles lineales. En modelos no lineales, como los logísticos, la Fórmula 1 no es útil porque la varianza en el nivel individual es heterocedastica (Raudenbush y Bryk 2002, p. 298). Tuvimos que realizar la alternativa propuesta por Snijders y Bosker (1999), que trata la variable dependiente como una medida continua latente siguiendo una distribución logística. La fórmula es la siguiente: 


\section{Fórmula 2}

$$
\rho=\frac{\tau_{00}}{\tau_{00}+\pi^{2} / 3}
$$

En nuestro modelo incondicional $11 \%$ de la variación en la probabilidad de apoyo a la comunidad se debe a factores localizados en el nivel de los países, lo que nos lleva a concluir por la estructura multinivel del fenómeno.

A partir de esos resultados construimos un modelo que combina predictores de nivel individual y nacional (Tabla 3). Este modelo indicó que la edad tiene un efecto positivo (aunque pequeño), la escolaridad tiene efecto negativo y el género (ser mujer) afecta positivamente la razón de probabilidad de apoyar a la comunidad política. En relación con las variables de nivel macro, el efecto de IDH es muy alto, indicando que el apoyo a la comunidad política en la región es fuertemente condicionado por el bienestar económico y social, mientras que la medida de Freedom House no es significativa. Los años de democracia ininterrumpida presentan efecto positivo.

Tabla 3

Condicionantes individuales y nacionales do apoyo a la comunidad política

\begin{tabular}{|l|c|c|c|}
\hline Variables & Coeficiente & Razón de probabilidad & Desviación estándar \\
\hline Nivel individual & & & \\
\hline Edad & $0,006 * * *$ & 1,006 & 0,001 \\
\hline Escolaridad & $-0,019^{* *}$ & 0,981 & 0,007 \\
\hline Sexo & $0,018^{* *}$ & 1,018 & 0,081 \\
\hline Nivel nacional & & & 0,081 \\
\hline IDH & $3,521 * * *$ & 33,818 & 0,079 \\
\hline Freedom House & 0,006 & 1,006 & 0,007 \\
\hline $\begin{array}{l}\text { Años de democracia } \\
\text { ininterrumpida }\end{array}$ & $0,047 * * *$ & 1,048 & 1,14 \\
\hline Constante & $-0,183$ & 0,833 & \\
\hline N nivel 1 & 38630 & & \\
\hline N nivel 2 & 24 & & \\
\hline Funte: Elabori & & \\
\hline
\end{tabular}

Fuente: Elaboración propia sobre la base de datos de Lapop, 2010.

Nota: $* * *$ significativo al nivel de $0.000 ; * *$ significativo al nivel de $0.001 ; *$ significativo al nivel de 0.05. Condition Index $<, 30$.

En relación con la dimensión de los principios del régimen, nuestro modelo incondicional encontró que $12.3 \%$ de variación de la razón en el índice de apoyo a los principios del régimen se debe a factores localizados en el nivel macro.

Luego de la confirmación de esa estructura jerárquica, construimos el modelo completo que se presenta abajo (Tabla 4). Los resultados indican que la edad afecta positivamente el apoyo a los principios: por más la edad, más la adhesión a esa dimensión. Mujeres y ciudadanos con más escolaridad tienden a adherirse con menos intensidad. En el nivel macro, solo los años de democracia ininterrumpida alcanzó la significancia mínima exigida, indicando que cuanto mayor el número de años, mayor adhesión de los ciudadanos a los principios. 
Tabla 4

Condicionantes individuales y nacionales de apoyo a los principios del régimen

\begin{tabular}{|l|c|c|c|}
\hline Variables & Coeficiente & Razón de probabilidad & Desviación estándar \\
\hline Nivel individual & & & 0.004 \\
\hline Edad & $0.011^{* *}$ & 0.017 & $0.011^{* *}$ \\
\hline Escolaridad & $0.150^{* * *}$ & 0.235 & $-0.552^{* *}$ \\
\hline Sexo & $-0.552^{* *}$ & & 2.168 \\
\hline Nivel nacional & & 4.032 & -0.707 \\
\hline IDH & 2.168 & 0.418 & $0.110^{* *}$ \\
\hline Freedom House & -0.707 & 0.029 & -0.053 \\
\hline $\begin{array}{l}\text { Años de democracia } \\
\text { ininterrumpida }\end{array}$ & $0.110^{* *}$ & 0.039 & 16.056 \\
\hline Constante & -0.053 & 2.609 & 38630 \\
\hline N nivel 1 & 16.056 & & \\
\hline N nivel 2 & 38630 & & \\
\hline
\end{tabular}

Fuente: Elaboración propia sobre la base de datos de Lapop, 2010.

Nota: $* * *$ significativo al nivel de $0.000 ; * *$ significativo al nivel de $0.001 ; *$ significativo al nivel de 0.05 .

En lo que se refiere a las instituciones, con el modelo nulo podemos verificar que la variación que se debe al nivel dos es menor en esa dimensión (8.9\%). A pesar de eso, creemos que ese porcentaje continúa justificando la adopción del modelo multinivel.

Analizando el modelo completo (Tabla 5), constatamos que la edad y escolaridad tienen efecto positivo, elevando el apoyo, mientras el género tiene efecto negativo, en otras palabras, las mujeres tienden a apoyar menos esta dimensión. Las variables estructurales fueron relevantes, lo que indica que el $8 \%$ que se debe a ese nivel lo poseen otros determinantes que no son parte de las hipótesis con las que trabajamos en este artículo. 
Tabla 5

Condicionantes individuales y nacionales de apoyo a las instituciones

\begin{tabular}{|l|c|c|}
\hline Variables & Coeficiente & Desviación estándar \\
\hline Nivel individual & & \\
\hline Edad & $0.011^{* *}$ & 0.004 \\
\hline Escolaridad & $0.150^{* * *}$ & 0.017 \\
\hline Sexo & $-0.552^{* *}$ & 0.235 \\
\hline Nivel nacional & & 6.433 \\
\hline IDH & -1.924 & 0.486 \\
\hline Freedom House & -0.533 & 0.054 \\
\hline $\begin{array}{l}\text { Años de democracia } \\
\text { ininterrumpida }\end{array}$ & 0.010 & 0.045 \\
\hline Constante & -0.051 & 5.219 \\
\hline N nivel 1 & $31.862 * * *$ & \\
\hline N nivel 2 & 38630 & \\
\hline
\end{tabular}

Fuente: Elaboración propia sobre la base de datos de Lapop, 2010.

Nota: $* * *$ significativo al nivel de $0.000 ; * *$ significativo al nivel de $0.001 ; *$ significativo al nivel de 0.05; Condition Index $<, 30$.

Con relación a la dimensión del desempeño, el modelo nulo indicó que $10.4 \%$ de la variación en el apoyo a la dimensión se debe a factores del nivel macro.

El análisis de los condicionantes (Tabla 6 ) indicó de esta vez que la edad tiene efecto negativo, o sea, a medida que avanza reduce el apoyo a esta dimensión. La escolaridad tiene efecto inverso, cuanto más escolarizado más positiva tiende a ser la evaluación del desempeño. En el nivel macro apenas los años de democracia fueron relevantes, presentando un efecto negativo.

Tabla 6

Condicionantes individuales y nacionales de apoyo al desempeño

\begin{tabular}{|c|c|c|}
\hline Variables & Coeficiente & Desviación estándar \\
\hline \multicolumn{3}{|l|}{ Nivel individual } \\
\hline Edad & $-0.003 * * *$ & 0.001 \\
\hline Escolaridad & $0.016 * *$ & 0.005 \\
\hline Sexo & -0.046 & 0.041 \\
\hline \multicolumn{3}{|l|}{ Nivel nacional } \\
\hline IDH & 0.257 & 1.228 \\
\hline Freedom House & -0.043 & 0.069 \\
\hline $\begin{array}{l}\text { Años de democracia } \\
\text { ininterrumpida }\end{array}$ & $-0.022 *$ & 0.009 \\
\hline Constante & $0.026 *$ & 0.012 \\
\hline $\mathrm{N}$ nivel 1 & $2.279 * *$ & 0.766 \\
\hline $\mathrm{N}$ nivel 2 & 38630 & \\
\hline
\end{tabular}

Fuente: Elaboración propia sobre la base de datos de Lapop, 2010. Nota: $* * *$ significativo al nivel de $0.000 ; * *$ significativo al nivel de $0.001 ; *$ significativo al nivel de 0.05 . Condition Index $<, 30$.

Con respecto a la dimensión del gobierno local, el peso de las variables nacionales es menor $(4.9 \%)$, lo que podemos considerar como razonable, ya que se trata de una 
dimensión ligada al nivel local. Aquí la justificación puramente estadística para la construcción del modelo contenido (condicionantes de nivel uno y dos) es efectivamente frágil, sin embargo, para mantener la misma lógica de los análisis de hipótesis adoptados en las dimensiones anteriores, optamos por continuar con el procedimiento estándar.

En el análisis de los condicionantes de ese apoyo, ninguna de las variables del nivel uno produjo efecto significativo (Tabla 7). Eso es particularmente preocupante, ya que como el modelo nulo indicó, es justamente en ese nivel que están los factores explicativos de la variación en el índice. Nuestro interés en este artículo no es producir modelos robustos para explicar esa dimensión de la legitimidad, sino apenas llamar la atención para la necesidad de investigación más detallada sobre qué factores de nivel micro condicionan el apoyo al gobierno local. En el nivel 2, el IDH y Freedom House producen efecto positivo, sobre todo el IDH, ya que la evaluación positiva del gobierno local está fuertemente ligada a condiciones objetivas favorables.

Tabla 7

Condicionantes individuales y nacionales de apoyo al gobierno local

\begin{tabular}{|l|c|c|}
\hline Variables & Coeficiente & Desviación estándar \\
\hline Nivel individual & -0.000 & 0.001 \\
\hline Edad & 0.011 & 0.007 \\
\hline Escolaridad & 0.015 & 0.080 \\
\hline Sexo & $2.963^{*}$ & 1.116 \\
\hline Nivel nacional & $0.161^{*}$ & 0.051 \\
\hline IDH & -0.009 & 0.009 \\
\hline Freedom House & -0.006 & 0.009 \\
\hline $\begin{array}{l}\text { Años de } \\
\text { democracia } \\
\text { ininterrumpida }\end{array}$ & $3.134^{* *}$ & 0.856 \\
\hline Constante & 38630 & \\
\hline N nivel 1 & N nivel 2 &
\end{tabular}

Fuente: Elaboración propia sobre la base de datos de Lapop, 2010.

Nota: *** significativo al nivel de $0.000 ; * *$ significativo al nivel de $0.001 ; *$ significativo al nivel de 0.05. Condition Index $<, 30$.

En cuanto a la dimensión relativa a los líderes y actores políticos verificamos que los factores ligados al nivel dos vuelven a ser más relevantes (8.2\%). Entre los condicionantes del nivel micro, apenas la variable escolaridad fue relevante, indicando que los más escolarizados son más críticos a la actuación del actual gobierno y del presidente (Tabla 8). Con respecto al nivel macro, los años de democracia ininterrumpida es la única variable relevante, produciendo reducción en el apoyo: cuanto más antigua la democracia, peor la evaluación de sus ciudadanos en relación a la actuación de líderes y actores políticos. 
LUCIANA FERNANDES VEIGA; EDNALDO RIBEIRO; MARÍA ALEJANDRA NICOLÁS; RACHEL CALLAI BRAGATTO

Tabla 8

\section{Condicionantes individuales y nacionales de apoyo a los líderes 0 actores políticos}

\begin{tabular}{|l|c|c|}
\hline Variables & Coeficiente & Desviación estándar \\
\hline Nivel individual & & \\
\hline Edad & 0.004 & 0.005 \\
\hline Escolaridad & $-0.120^{*}$ & 0.033 \\
\hline Sexo & -0.216 & 0.037 \\
\hline Nivel nacional & & \\
\hline IDH & 1.992 & 3.278 \\
\hline Freedom House & 0.002 & 0.427 \\
\hline $\begin{array}{l}\text { Años de democracia } \\
\text { ininterrumpida }\end{array}$ & $-0.077 *$ & 0.036 \\
\hline Constante & $15.927 * * *$ & 3.031 \\
\hline N nivel 1 & 38630 & \\
\hline N nivel 2 & 24 & \\
\hline
\end{tabular}

Fuente: Elaboración propia sobre la base de datos de Lapop, 2010. Nota: *** significativo al nivel de $0.000 ; * *$ significativo al nivel de $0.001 ; *$ significativo al nivel de 0.05 . Condition Index $<, 30$.

Se verificó que no solo existen diferentes dimensiones de la legitimidad del régimen como también hay distintas fuentes para la legitimidad, las cuales varían de las más abstractas a las más concretas y poseen fuentes bien diversificadas tanto a nivel estructural cómo a nivel individual - así como apuntaba Booth y Seligson (2009). En otras palabras, que una fuente impacte en una dimensión no impacta necesariamente en las demás.

Sobre las dimensiones de la legitimidad se constató, en lo que se refiere a su distribución, que es mayor el apoyo difuso que el apoyo específico cuando tomamos todos los países latinoamericanos y caribeños. Lo anterior es consistente con estudios anteriores que sólo estudiaron una submuestra de los países de la región.

Sobre el primer conjunto de hipótesis que examina las dimensiones difusas de la legitimidad, encontramos evidencia que a mayor edad, el apoyo difuso a la democracia se incrementa. Entre las seis dimensiones de la legitimidad, existe una asociación entre las dimensiones difusas (apoyo a la comunidad política y apoyo a los principios del régimen) y edad (efecto significativo y positivo): a mayor edad aumenta el apoyo difuso a la democracia. Estos hallazgos son consistentes con el análisis de Morlino (2007) y Booth y Seligson (2009), que observan que la experiencia con regímenes no democráticos (y el recuerdo de los momentos de represión) pueden aumentar la percepción de la democracia como un valor.

En lo que se refiere a la experiencia democrática de cada país, los años de democracia ininterrumpidos se mostraron relevantes para el apoyo a las dimensiones más abstractas (apoyo a la comunidad política y a los principios del régimen). No obstante, contraria a nuestras expectativas, el efecto es positivo: a mayor número de años de democracia ininterrumpida, mayor apoyo difuso. Es decir, la acumulación de la experiencia ininterrumpida del país con el régimen democrático, y no el recuerdo del pasado represivo, está asociada a la adhesión de la democracia en el sentido más difuso. 
En relación con el segundo conjunto de hipótesis, que evalúa las dimensiones específicas de la legitimidad, contrario también a nuestras expectativas, el efecto de la edad del ciudadano impacta en apenas dos de las cuatro dimensiones más específicas: apoyo a las instituciones y al desempeño del régimen. Las dos restantes, apoyo a las autoridades o actores políticos y apoyo al gobierno local, no presentan impacto significativo. Además, la edad del ciudadano tiene impacto negativo en el apoyo al desempeño del régimen. Si esperábamos que los ciudadanos con mayor edad - por estar más habituados con las reglas, potencialidades y limitaciones democráticas - reportaran mayor apoyo al régimen en el aspecto de la eficiencia, en realidad ocurre lo contrario: los ciudadanos con mayor edad son los que menos apoyo reportaron en relación con el desempeño de la democracia.

El efecto de la acumulación de los años ininterrumpidos de democracia se mostró significativo y negativo en dos de las dimensiones específicas: apoyo al desempeño del régimen y apoyo a autoridades o actores políticos. No fue significativo en lo que se refiere al apoyo a las instituciones políticas y al gobierno local. Los resultados no confirman la hipótesis que a más experiencia democrática llevaría a más adhesión a la dimensión específica. Los avances que surgieron con la "tercera ola" de democratización - que conducen al establecimiento de normas que introducen previsibilidad a las reglas de juego - no garantizan apoyo al régimen democrático, como ya refería Baquero (2011a y b).

\section{Consideraciones finales}

Consistente con estudios previos, destaca que diferentes fuentes de legitimidad impactan de manera específica en cada una de las dimensiones de la estructura de la legitimidad. Concretamente, en lo que se refiere a nuestras hipótesis, así como Booth y Seligson (2009) desarrollaron en su investigación, el número de años de democracia ininterrumpida impacta de manera positiva el apoyo a la comunidad política y a los principios centrales del régimen. Además, la evaluación del desempeño del régimen se ve afectada de forma negativa. Mientras no tiene ningún apelo en las otras dimensiones.

En otras palabras, la experiencia democrática ininterrumpida del país está asociada a la adhesión al régimen en el sentido más difuso. Este resultado es contrario a nuestra hipótesis, pues nuestra premisa inicial a partir de Morlino (2007), argumentaba que el recuerdo de experimentar regímenes no democráticos llevaría al apoyo más difuso de la democracia. Este, tal vez haya sido el hallazgo más interesante de este estudio por el hecho de traer una esperanza para el fortalecimiento de la democracia en la región. Si nuestras expectativas creadas a partir de la revisión de la teoría hubieran sido confirmadas, la adhesión más difusa al régimen democrático estaría bajo amenaza de reducción cada año que éste se alejara de la época de la dictadura. Al contrario, para nuestro aliento, la experiencia con la democracia generada después de la "tercera ola" ha fortalecido las dos dimensiones más difusas del régimen: apoyo a la comunidad política y apoyo a los principios democráticos. Este hallazgo coloca en suspenso el argumento de Baquero 
(2011a) que apunta que el desencanto de los latinoamericanos con el funcionamiento de la democracia, con políticas perjudiciales e interrupciones autoritarias, disminuyó la posibilidad de cultivar una base de apoyo normativo a la democracia.

En lo que se refiere al apoyo más específico, no se confirmó la hipótesis derivada a partir de la discusión de Moisés y Carneiro (2010), de acuerdo con la cual, a mayor número de años de experiencia democrática llevaría a instituciones más maduras y a ciudadanos más habituados con el ritmo y el accionar de la democracia. En lo que se refiere a la edad, nuestras hipótesis fueron parcialmente confirmadas. A mayor edad y más experiencia con el régimen democrático resultó en más adhesión en las dimensiones de: a) el apoyo a la comunidad política; b) los principios centrales del régimen; y c) el apoyo a las instituciones. Sobre la evaluación del régimen, el resultado fue negativo: a mayor edad, los ciudadanos son más críticos en su evaluación al régimen. En otras palabras, los ciudadanos de mayor edad, más conocedores del papel de las instituciones y de la necesidad de los gobiernos de rendir cuentas, evalúan de forma más negativa el régimen. De hecho, este resultado es desalentador para el avance de la consolidación democrática en la región. De cualquier forma, es necesario explorar en futuros estudios las razones de dicha asociación. En conclusión, destaca la importancia de la experiencia democrática más allá de la "tercera ola" como efecto positivo para el incremento del apoyo a la dimensión práctica del régimen.

Los resultados de este estudio también destacan otro tema relevante, aunque este no sea el punto central de nuestro artículo. La escolaridad ejerce influencia positiva y significativa en las dimensiones consideradas centrales para la legitimidad de la democracia: apoyo a los principios del régimen, apoyo a instituciones políticas y al desempeño del régimen. Sin embargo, la escolaridad ejerce influencia negativa y significativa en la dimensión de apoyo a autoridades y actores políticos. Esto nos lleva a desarrollar un argumento: el apoyo a las autoridades y actores políticos puede ser una puerta de entrada de las personas con menos escolaridad para la adhesión a la legitimidad de la democracia, ya que las mismas tienden a ser más críticas con relación a los principios, instituciones y desempeño del régimen.

Luciana Fernandes Veiga - Profesora de Ciencia Política, Coordinadora del Programa de Pósgrado en Ciencia Política, Universidad Federal del Estado de Rio de Janeiro (Unirio), Rio de Janeiro, Brasil. E-mail: <luciana.veiga@unirio.br>.

Ednaldo Ribeiro - Profesor de Ciencia Política, Departamento de Ciencias Sociales, Universidad Estatal de Maringá (UEM), Maringá, Brasil. E-mail: <ednaldorip@uol.com.br>.

María Alejandra Nicolás - Profesora de Administración Pública y Políticas Públicas, Instituto Latino-Americano de Economía, Sociedad y Política (Ilaesp), Universidad Federal de la Integración Latino-Americana. E-mail: <alejandranicolas@gmail.com>.

Rachel Callai Bragatto - Doctora en Sociología, Universidad Federal de Paraná (UFPR), Curitiba, Brasil. E-mail: <rachelbragatto@gmail.com> 


\section{Referencias bibliográficas}

Almond, G.; VerbA, S. The civic culture: political attitudes and democracy in five nations. California: Sage Publications, 1989.

Anastasia, F.; Melo, R. C.; Santos, F. Governabilidade e representação política na América do Sul. Rio de Janeiro: Fundação Konrad Adenahuer/Fundação Unesp, 2004.

BAQUERO, M. A cultura política na agenda da democratização na América Latina. In: BAQUERO, M. Cultura(s) política(s) e democracia no século XXI na América Latina. Porto Alegre: Editora da UFRGS, p. 13-24, 2011 a.

. Padrões de constituição da cultura política na América Latina no século XXI. In: BAQUERO, M. Cultura(s) política(s) e democracia no século XXI na América Latina. Porto Alegre: Editora da UFRGS, p. 13-24, 2011b.

Booth, J.; Seligson, M. The legitimacy puzzle in Latin America: political support and democracy in eight nations. Cambridge: Cambridge University Press, 2009.

ChasquetTI, D. Democracia, multipartidarismo y coaliciones en América Latina: evaluando la difícil combinación. In: LANZARO, J. Tipos de presidencialismo y coaliciones políticas en América Latina. Buenos Aires: Clacso, p. 319-359, 2003.

Cheresky, I.; ChONCHOL, J. Crise e transformação dos regimes autoritários. Campinas: Ícone Editora Ltda./Editora da Unicamp, 1986.

DAHL. R. La poliarquia. Participación y oposición. Buenos Aires: Editorial Rei Argentina, 1989.

DALTON, R. Political support in advanced industrial countries. In: NorRIS, P. (ed.). Critical citizens: global support for democratic governance. UK: Oxford University Press, p. 57-78, 1999.

. Democratic challenges, democratic choices: the erosion of political support in advanced industrial democratic. Oxford: Oxford University Press, 2004.

EASTON, D. Esquema para el análisis político. Buenos Aires: Amorrortu Editores, 1999.

Gunther, R.; Monteiro, J. R. "Legitimidade política em novas democracias". Opinião Pública, Campinas, vol. 9, no 1, p. 1-43, mayo 2003.

Hair, J.; Anderson, R.; TAtham, R. Multivariate data analysis. New York: Macmillan Publishing, 1987. Huntington, S. A terceira onda. São Paulo: Ática, 1994.

KLingemanN, H. D. Mapping political support in the 1990s: a global analysis. In: NorRIS, P. (ed.). Critical citizens: global support for democratic governance. UK: Oxford University Press, p. 31-56, 1999.

LAgos, M. "A máscara sorridente da América Latina". Opinião Pública, Campinas, vol. 6, no 1, p. 116 , abril 2000.

Mainwaring, S. "Presidentialism in Latin America". Latin America Research Review, Pittsburgh, vol. 25 , no 1, p. 157-179, 1990.

MAINWARING, S.; ShugART, M. "Juan Linz, presidentialism, and democracy: a critical appraisal". Novos Estudos Cebrap, São Paulo, vol. 37, p. 191-213, 1993. 
LUCIANA FERNANDES VEIGA; EDNALDO RIBEIRO; MARÍA ALEJANDRA NICOLÁS; RACHEL CALLAI BRAGATTO

Moisés, J. Á. "Confiança e instituições democráticas". Lua Nova, São Paulo, n 65, p. 71-94, ene.abr. 2005.

MoIsÉs, J. Á. "Cultura política, instituições e democracia: lições da experiência brasileira". Revista Brasileira de Ciências Sociais, São Paulo, vol. 23, n 66, p. 11-43, feb. 2008.

. Cultura política, instituições e democracia - Lições da experiência brasileira. In: MoIsés, j. Á. (ed.). Democracia e confiança: por que os cidadãos desconfiam das instituições públicas?. São Paulo: Edusp, p. 77-121, 2010.

MoIsÉs, J. Á.; CARNEIRO, G. P. Democracia, desconfiança política e insatisfação com o regime - O caso do Brasil. In: MoIsés, J. Á. (ed.). Democracia e confiança: por que os cidadãos desconfiam das instituições públicas? São Paulo: Edusp, p. 149-184, 2010.

MoRLINo, L. "Explicar la calidad democrática ¿Qué tan relevantes son las tradiciones autoritarias?". Revista de Ciencia Política, Chile, vol. 27, n², p. 3-22, 2007.

Muller, E.; Seligson, M. A. "Civic culture and democracy: the question of causal relationships". American Political Science Review, Washington, vol. 88, no 3, p. 635-652, sep. 1994.

NORRIS, P. Critical citizens: global support for democratic governance. UK: Oxford University Press, 1999.

O’DonnelL, G. "Democracia delegativa". Novos Estudos Cebrap, São Paulo, vol. 31, p. 25-40, 1991.

PUTNAM, R. D. Bowling alone: the collapse and revival of American community. New York: Simon \& Schuster Paperbacks, 2000.

RAUDENBUSH, S. W.; BRYK, A. S. Hierarchical linear models: applications and data analysis methods. EUA: Sage Publications, 2002.

RibeIRo, E. A. "As dimensões da legitimidade democrática no Brasil". Revista Teoria e Sociedade, Belo Horizonte, n 16, vol. 1, p. 120-143, ene.-jun. 2008.

Seligson, M. A.; Booth, J. A.; Gómez, M. B. "Os contornos da cidadania crítica: explorando a legitimidade democrática". Opinião Pública, São Paulo, vol. 12, nº 1, p. 1-37, abr.-mayo 2006.

SмIтH, P. Democracy in Latin America: political change in comparative perspective. New York: Oxford University Press, 2005.

SNIJDERS, T. A. B.; BOSKER, R. J. Multilevel analysis: an introduction to basic and advanced multilevel modeling. California: Sage, 1999. 
Anexo

\begin{tabular}{|c|c|c|c|c|c|}
\hline \multicolumn{6}{|c|}{ Estadísticas descriptivas } \\
\hline País & $\mathbf{N}$ & Mínimo & Máximo & Media & Desvío estándar \\
\hline \multirow[t]{6}{*}{ México } & Comunidad política & 1495 & 0 & 1 & 0,9 \\
\hline & Principios del régimen & 1463 & 0 & 27 & 18,12 \\
\hline & Instituciones políticas & 1265 & 0 & 54 & 28,76 \\
\hline & Desempeño & 1477 & 0 & 6 & 2,19 \\
\hline & Autoridades y actores & 1370 & 0 & 34 & 16,41 \\
\hline & Gobierno local & 1455 & 0 & 10 & 5,46 \\
\hline \multirow[t]{6}{*}{ Guatemala } & Comunidad política & 1490 & 0 & 1 & 0,84 \\
\hline & Principios del régimen & 1415 & 0 & 27 & 16,17 \\
\hline & Instituciones políticas & 1252 & 0 & 54 & 26,21 \\
\hline & Desempeño & 1475 & 0 & 6 & 2,27 \\
\hline & Autoridades y actores & 1199 & 0 & 34 & 15,23 \\
\hline & Gobierno local & 1442 & 0 & 10 & 5,41 \\
\hline \multirow[t]{6}{*}{ El Salvador } & Comunidad política & 1480 & 0 & 1 & 0,94 \\
\hline & Principios del régimen & 1410 & 0 & 27 & 17,58 \\
\hline & Instituciones políticas & 1202 & 0 & 54 & 28,37 \\
\hline & Desempeño & 1455 & 0 & 6 & 1,84 \\
\hline & Autoridades y actores & 1288 & 0 & 34 & 17,67 \\
\hline & Gobierno local & 1391 & 0 & 10 & 5,78 \\
\hline \multirow[t]{6}{*}{ Honduras } & Comunidad política & 1485 & 0 & 1 & 0,81 \\
\hline & Principios del régimen & 1360 & 0 & 27 & 13,44 \\
\hline & Instituciones políticas & 1272 & 0 & 54 & 20,56 \\
\hline & Desempeño & 1479 & 0 & 6 & 2,21 \\
\hline & Autoridades y actores & 1359 & 0 & 34 & 11,06 \\
\hline & Gobierno local & 1432 & 0 & 10 & 4,88 \\
\hline \multirow[t]{6}{*}{ Nicaragua } & Comunidad política & 1498 & 0 & 1 & 0,97 \\
\hline & Principios del régimen & 1483 & 0 & 27 & 21,82 \\
\hline & Instituciones políticas & 1358 & 0 & 54 & 29,93 \\
\hline & Desempeño & 1473 & 0 & 6 & 2,88 \\
\hline & Autoridades y actores & 1402 & 0 & 34 & 21,06 \\
\hline & Gobierno local & 1425 & 0 & 10 & 5,42 \\
\hline \multirow[t]{5}{*}{ Costa Rica } & Comunidad política & 1452 & 0 & 1 & 0,89 \\
\hline & Principios del régimen & 1457 & 0 & 27 & 20,36 \\
\hline & Instituciones políticas & 1292 & 0 & 54 & 26,76 \\
\hline & Desempeño & 1477 & 0 & 6 & 2,45 \\
\hline & Autoridades y actores & 1402 & 0 & 34 & 13,51 \\
\hline
\end{tabular}


LUCIANA FERNANDES VEIGA; EDNALDO RIBEIRO; MARÍA ALEJANDRA NICOLÁS; RACHEL CALLAI BRAGATTO

\begin{tabular}{|c|c|c|c|c|c|}
\hline & Gobierno local & 1420 & 0 & 10 & 4,86 \\
\hline \multicolumn{6}{|c|}{ Estadísticas descriptivas } \\
\hline País & $\mathbf{N}$ & Mínimo & Máximo & Media & Desvío estándar \\
\hline \multirow[t]{6}{*}{ Panamá } & Comunidad política & 1492 & 0 & 1 & 0,96 \\
\hline & Principios del régimen & 1402 & 0 & 27 & 16,81 \\
\hline & Instituciones políticas & 1332 & 0 & 54 & 23,84 \\
\hline & Desempeño & 1475 & 0 & 6 & 2,88 \\
\hline & Autoridades y actores & 1419 & 0 & 34 & 14,4 \\
\hline & Gobierno local & & 0 & 10 & 4,6 \\
\hline \multirow[t]{6}{*}{ Colombia } & Comunidad política & 1491 & 0 & 1 & 0,94 \\
\hline & Principios del régimen & 1411 & 0 & 27 & 18,72 \\
\hline & Instituciones políticas & 1217 & 0 & 54 & 26,92 \\
\hline & Desempeño & 1459 & 0 & 6 & 2,63 \\
\hline & Autoridades y actores & 1317 & 0 & 34 & 16,46 \\
\hline & Gobierno local & 1431 & 0 & 10 & 5,1 \\
\hline \multirow[t]{6}{*}{ Ecuador } & Comunidad política & 1480 & 0 & 1 & 0,89 \\
\hline & Principios del régimen & 1434 & 0 & 27 & 15,87 \\
\hline & Instituciones políticas & 1151 & 0 & 54 & 24,85 \\
\hline & Desempeño & 1466 & 0 & 6 & 3,23 \\
\hline & Autoridades y actores & 1415 & 0 & 34 & 19,93 \\
\hline & Gobierno local & 1432 & 0 & 10 & 5,23 \\
\hline \multirow[t]{6}{*}{ Bolivia } & Comunidad política & 1487 & 0 & 1 & 0,88 \\
\hline & Principios del régimen & 1382 & 0 & 27 & 14,95 \\
\hline & Instituciones políticas & 1201 & 0 & 54 & 23,88 \\
\hline & Desempeño & 1478 & 0 & 6 & 2,66 \\
\hline & Autoridades y actores & 1339 & 0 & 34 & 15,18 \\
\hline & Gobierno local & 1406 & 0 & 10 & 4,82 \\
\hline \multirow[t]{6}{*}{ Perú } & Comunidad política & 1486 & 0 & 1 & 0,88 \\
\hline & Principios del régimen & 1461 & 0 & 27 & 17,28 \\
\hline & Instituciones políticas & 1389 & 0 & 54 & 23,94 \\
\hline & Desempeño & 1472 & 0 & 6 & 2,92 \\
\hline & Autoridades y actores & 1373 & 0 & 34 & 16,03 \\
\hline & Gobierno local & 1428 & 0 & 10 & 4,34 \\
\hline \multirow[t]{6}{*}{ Paraguay } & Comunidad política & 1451 & 0 & 1 & 0,94 \\
\hline & Principios del régimen & 1454 & 0 & 27 & 20,86 \\
\hline & Instituciones políticas & 1227 & 0 & 54 & 22,75 \\
\hline & Desempeño & 1471 & 0 & 6 & 2,65 \\
\hline & Autoridades y actores & 1353 & 0 & 34 & 14,03 \\
\hline & Gobierno local & 1427 & 0 & 10 & 5,39 \\
\hline \multirow[t]{2}{*}{ Chile } & Comunidad política & 1480 & 0 & 1 & 0,78 \\
\hline & Principios del régimen & 1445 & 0 & 27 & 19 \\
\hline
\end{tabular}




\begin{tabular}{|c|c|c|c|c|c|}
\hline \multicolumn{6}{|c|}{ Estadísticas descriptivas } \\
\hline País & $\mathbf{N}$ & Mínimo & Máximo & Media & Desvío estándar \\
\hline \multirow[t]{4}{*}{ Chile } & Instituciones políticas & 1359 & 0 & 54 & 28,27 \\
\hline & Desempeño & 1489 & 0 & 6 & 2,77 \\
\hline & Autoridades y actores & 1391 & 0 & 34 & 16,24 \\
\hline & Gobierno local & 1377 & 0 & 10 & 5,69 \\
\hline \multirow[t]{6}{*}{ Uruguay } & Comunidad política & 1487 & 0 & 1 & 0,9 \\
\hline & Principios del régimen & 1461 & 0 & 27 & 22,15 \\
\hline & Instituciones políticas & 1213 & 0 & 54 & 31,35 \\
\hline & Desempeño & 1440 & 0 & 6 & 3,52 \\
\hline & Autoridades y actores & 1297 & 0 & 34 & 20,08 \\
\hline & Gobierno local & 1420 & 0 & 10 & 5,19 \\
\hline \multirow[t]{6}{*}{ Brasil } & Comunidad política & 1490 & 0 & 1 & 0,79 \\
\hline & Principios del régimen & 1468 & 0 & 27 & 17,8 \\
\hline & Instituciones políticas & 1385 & 0 & 54 & 23,83 \\
\hline & Desempeño & 1456 & 0 & 6 & 3,18 \\
\hline & Autoridades y actores & 1411 & 0 & 34 & 15,96 \\
\hline & Gobierno local & 1467 & 0 & 10 & 4,48 \\
\hline \multirow[t]{6}{*}{ Venezuela } & Comunidad política & 1494 & 0 & 1 & 0,94 \\
\hline & Principios del régimen & 1453 & 0 & 27 & 19,57 \\
\hline & Instituciones políticas & 1320 & 0 & 54 & 28,69 \\
\hline & Desempeño & 1452 & 0 & 6 & 2,75 \\
\hline & Autoridades y actores & 1400 & 0 & 34 & 17,53 \\
\hline & Gobierno local & 1276 & 0 & 10 & 5,61 \\
\hline \multirow[t]{6}{*}{ Argentina } & Comunidad política & 1481 & 0 & 1 & 0,9 \\
\hline & Principios del régimen & 1466 & 0 & 27 & 18,82 \\
\hline & Instituciones políticas & 1248 & 0 & 54 & 27,48 \\
\hline & Desempeño & 1460 & 0 & 6 & 2,87 \\
\hline & Autoridades y actores & 1387 & 0 & 34 & 15,63 \\
\hline & Gobierno local & 1431 & 0 & 10 & 5,61 \\
\hline \multirow[t]{6}{*}{ Rep. Dom. } & Comunidad política & 1491 & 0 & 1 & 0,94 \\
\hline & Principios del régimen & 1443 & 0 & 27 & 21,03 \\
\hline & Instituciones políticas & 1356 & 0 & 54 & 25,24 \\
\hline & Desempeño & 1476 & 0 & 6 & 1,75 \\
\hline & Autoridades y actores & 1395 & 0 & 34 & 14,05 \\
\hline & Gobierno local & 1436 & 0 & 10 & 4,64 \\
\hline \multirow[t]{2}{*}{ Haití } & Comunidad política & 1441 & 0 & 1 & 0,76 \\
\hline & Principios del régimen & 1448 & 0 & 27 & 15,93 \\
\hline
\end{tabular}


LUCIANA FERNANDES VEIGA; EDNALDO RIBEIRO; MARÍA ALEJANDRA NICOLÁS; RACHEL CALLAI BRAGATTO

\begin{tabular}{|c|c|c|c|c|c|}
\hline & Instituciones políticas & 1406 & 1 & 46 & 22,02 \\
\hline & Desempeño & 1419 & 0 & 5 & 2,08 \\
\hline \multicolumn{6}{|c|}{ Estadísticas descriptivas } \\
\hline País & $\mathbf{N}$ & Mínimo & Máximo & Media & Desvío estándar \\
\hline \multirow[t]{2}{*}{ Haití } & Autoridades y actores & 1381 & 0 & 34 & 15,88 \\
\hline & Gobierno local & 1347 & 0 & 9 & 3,66 \\
\hline \multirow[t]{6}{*}{ Jamaica } & Comunidad política & 1496 & 0 & 1 & 0,93 \\
\hline & Principios del régimen & 1465 & 2 & 27 & 20,05 \\
\hline & Instituciones políticas & 1265 & 0 & 54 & 29,06 \\
\hline & Desempeño & 1418 & 0 & 6 & 2,28 \\
\hline & Autoridades y actores & 1190 & 0 & 34 & 15,94 \\
\hline & Gobierno local & 1255 & 0 & 10 & 4,43 \\
\hline \multirow[t]{6}{*}{ Guyana } & Comunidad política & 1489 & 0 & 1 & 0,86 \\
\hline & Principios del régimen & 1466 & 0 & 27 & 21,13 \\
\hline & Instituciones políticas & 1255 & 0 & 54 & 31,05 \\
\hline & Desempeño & 1451 & 0 & 6 & 3,12 \\
\hline & Autoridades y actores & 1142 & 0 & 34 & 16,33 \\
\hline & Gobierno local & 1359 & 0 & 10 & 4,81 \\
\hline \multirow[t]{6}{*}{$\begin{array}{l}\text { Trinidad y } \\
\text { Tobago } \\
\end{array}$} & Comunidad política & 1483 & 0 & 1 & 0,87 \\
\hline & Principios del régimen & 1375 & 0 & 27 & 21,58 \\
\hline & Instituciones políticas & 1167 & 0 & 54 & 25,38 \\
\hline & Desempeño & 1414 & 0 & 6 & 2,72 \\
\hline & Autoridades y actores & 1295 & 0 & 34 & 14,08 \\
\hline & Gobierno local & 1289 & 0 & 10 & 4,41 \\
\hline \multirow[t]{6}{*}{ Belice } & Comunidad política & 1492 & 0 & 1 & 0,95 \\
\hline & Principios del régimen & 1457 & 0 & 27 & 21,05 \\
\hline & Instituciones políticas & 1315 & 0 & 54 & 32,84 \\
\hline & Desempeño & 1479 & 0 & 6 & 2,41 \\
\hline & Autoridades y actores & 1366 & 0 & 34 & 17,31 \\
\hline & Gobierno local & 1414 & 0 & 10 & 5,06 \\
\hline \multirow[t]{6}{*}{ Surinam } & Comunidad política & 1474 & 0 & 1 & 0,96 \\
\hline & Principios del régimen & 1326 & 0 & 27 & 19,22 \\
\hline & Instituciones políticas & 1022 & 0 & 54 & 33,75 \\
\hline & Desempeño & 1400 & 0 & 6 & 2,92 \\
\hline & Autoridades y actores & 1161 & 0 & 34 & 19,76 \\
\hline & Gobierno local & 871 & 0 & 10 & 5,2 \\
\hline
\end{tabular}

Fuente: Elaboración propia sobre la base de datos de Lapop, 2010. 


\section{Resumen \\ El efecto de la experiencia democrática en la estructura de la legitimidad en América Latina y el Caribe}

Este estudio se enfoca en una paradoja en América Latina y el Caribe: el aumento progresivo de la adhesión a la democracia pero una creciente disminución de la satisfacción con el sistema. ¿EI factor temporal podría explicar tal contradicción? Este artículo muestra que la edad de los ciudadanos y los años de experiencia democrática de cada país influyen en las disposiciones individuales en relación a la democracia en términos de apoyos difuso y específico. Aplicamos análisis factorial y un modelo multinivel de regresión multivariada. Nuestro estudio presenta evidencia de la relación entre la experiencia con el régimen democrático y el apoyo a las dimensiones más difusas de la legitimidad; esta relación no se encontró en las dimensiones más específicas.

Palabras clave: democracia, legitimidad democrática, América Latina y Caribe, apoyo difuso y específico, regímenes autoritarios

\section{Resumo}

O efeito da experiência democrática na estrutura da legitimidade na América Latina e no Caribe

Este artigo refere-se a um paradoxo hoje presente na América Latina e no Caribe: verifica-se o aumento progressivo da adesão à democracia mas uma crescente diminuição da satisfação com o sistema. O fator temporal poderia explicar essa contradição? O artigo apresenta como a idade dos cidadãos e os anos de experiência democrática das nações influenciam nas disposições individuas em relação à democracia em termos de apoios difuso e específico. Aplicamos análise fatorial e um modelo multinível de regressão multivariada. Nossos resultados demonstram a relação entre a experiência com o regime democrático e o apoio às dimensões mais difusas da legitimidade, porém isso não se confirmou nas dimensões mais específicas.

Palavras-chave: democracia, legitimidade democrática, América Latina e Caribe, apoio difuso e específico, regimes autoritários

\section{Abstract}

The effect of the democratic experience on the structure of legitimacy in Latin America and the Caribbean

The article refers to a paradox that is present in Latin America and the Caribbean nowadays: on the one hand, adherence to democracy has increased exponentially; on the other hand, satisfaction with the system has decreased substantially. Could the temporal factor explain this contradiction? This article presents how the age of citizens and the democratic longevity of Latin American countries influence individual provisions regarding democracy in terms of diffuse and specific support. We applied factor analysis and a multivariate multilevel model. Our results provide evidence for the relationship between experience with the democratic regime and support for the most diffuse dimensions of legitimacy, but this has not been confirmed for the more specific dimensions.

Keywords: democracy; democratic legitimacy; Latin America and the Caribbean; diffuse and specific support; authoritarian regimes

\section{Résumé}

L'effet de l'expérience démocratique dans la structure de la légitimité en Amérique Latine et aux Caraïbes 
LUCIANA FERNANDES VEIGA; EDNALDO RIBEIRO; MARÍA ALEJANDRA NICOLÁS; RACHEL CALLAI BRAGATTO

L'article fait référence à un paradoxe aujourd'hui présent en Amérique latine et aux Caraïbes: une augmentation constante dans l'adhésion à la démocratie avec une diminution croissante de la satisfaction envers le système. Le facteur temps pourrait-il expliquer cette contradiction? L'article montre comment l'âge des citoyens et les années d'expérience démocratique des pays ont de I'influence sur certaines dispositions relatives à la démocratie en termes de soutiens diffus et spécifique. Nous appliquons une analyse des facteurs à plusieurs niveaux et le modèle de régression à variables multiples. Les résultats démontrent la relation entre l'expérience de la démocratie et le soutien des dimensions les plus diffuses de légitimité, mais cela ne se confirme pas dans les dimensions les plus spécifiques.

Mots-clés: démocratie; légitimité démocratique; l'Amérique latine et les Caraïbes; soutien diffus et spécifique; régimes autoritaires

Artículo sometido para publicación el 4 de febrero de 2016.

Versión final aprobada el 24 de abril de 2017. 